\title{
MONTAGEM DO PENSAMENTO E DA ESCRITA ACADÊMICA EM EDUCAÇÃO: CONVERSAÇÕES ENTRE DELEUZE E DIDI-HUBERMAN
}

\author{
MONTAGE OF ACADEMIC THOUGHT AND WRITING IN EDUCATION: \\ SCONVERSATIONS BETWEEN DELEUZE AND DIDI-HUBERMAN
}

\author{
MONTAJE DEL PENSAMIENTO Y DE LA ESCRITA ACADÉMICA EN LA \\ EDUCACIÓN: CONVERSACIONES ENTRE DELEUZE Y DIDI-HUBERMAN
}

Elisandro Rodrigues ${ }^{1}$, Betina Schuler ${ }^{2}$

\begin{abstract}
RESUMO
Este artigo toma o conceito de montagem operado na filosofia e nas artes por Deleuze e Didi-Huberman, realizando certa extração para compor uma problematização da montagem do pensamento e da escrita em educação. Toma-se, assim, a montagem como procedimento filosófico, gesto político e criação artística. Quando escrevemos em educação, sobre educação, para educadores, produzimos imagens de pensamento por meio de tais produções. Interessa, então, apreender os funcionamentos desse conceito para operá-lo nos deslocamentos possíveis do que se pensa e se escreve em educação, em especial, na escrita acadêmica. Entendemos que tomar a escrita como montagem do pensamento poderia operar como certa problematização do pensamento dogmático em educação.
\end{abstract}

PALAVRAS-CHAVE: Montagem. Pensamento. Escrita Acadêmica. Educação.

\begin{abstract}
This article takes the concept of assemblage operated in philosophy and art by Deleuze and Didi-Huberman to do an extraction to compose a problematization of montage of thought and writing in education. This concept is taken as philosophical procedure, political gesture, and artistic creation. When we write in the field of education, about education, to educators, we produce images of thought by means of these productions. Then, we are interested in apprehending the functions of this concept to use it in possible displacements of what is thought and written in education, especially in academic writing. We understand that regarding writing as a montage of thought could function as a kind of problematization of the dogmatic thought in education.
\end{abstract}

KEYWORDS: Montage. Thought. Academic Writing. Education.

\section{RESUMEN}

Este artículo toma el concepto de montaje operado en la filosofía y en las artes por Deleuze y Didi-Huberman, realizando cierta extracción para componer una problematización del mismo y de la escrita en la educación. Se adopta, de esta manera, al montaje como procedimiento filosófico, gesto político y creación artística. Cuando escribimos sobre educación, para educadores, producimos imágenes de pensamiento por medio de tales producciones. Nos interesa, entonces, aprender los funcionamientos de ese concepto para operarlo en los dislocamientos posibles de lo que se piensa y se escribe en la educación, en especial en la escrita académica.

\footnotetext{
${ }^{1}$ Doutorando em Educação - Universidade do Vale do Rio (Unisinos) - São Leopoldo, RS - Brasil. Especialista em Tecnologias da Informação e da Comunicação Aplicadas à Educação; Pedagogo - Hospital Nossa Senhora da Conceição, Gerência de Ensino e Pesquisa - GEP - Porto Alegre, RS - Brasil. E-mail:

elisandromosaico@gmail.com

${ }^{2}$ Doutorado em Educação - Pontifícia Universidade Católica do Rio Grande do Sul (PUCRS) - Partenon, Porto Alegre, RS - Brasil. Professor Assistente - Universidade do Vale do Rio (Unisinos) - São Leopoldo, RS - Brasil. Email: betinaschuler@hotmail.com

Submetido em: 29/09/2017 - Aceito em: 11/06/2018
}

(C) ETD- Educação Temática Digital Campinas, SP $\quad$ v.21 n.1 $\quad$ p.23-46 jan./mar. 2019


Entendemos que tomar la escrita como un montaje del pensamiento podría operar como cierta problematización del pensamiento dogmático en la educación.

PALABRAS CLAVE: Montaje. Pensamiento. Escrita académica. Educación.

\section{FRAGMENTOS INICIAIS}

El montaje sería un método de conocimiento y un procedimiento formal nacido de la guerra, que toma acta del 'desorden del mundo'. (DIDI-HUBERMAN, 2013d, p. 77).

Como pensar a montagem? E por que colocar essa questão em educação? Porque talvez seja uma composição possível para pensar também a diferença em educação. Muitos autores, no Brasil e no mundo, vêm se apropriando do chamado pensamento da diferença para produzir algumas dobras na pesquisa em educação. Trata-se de uma postura de produzir alguns furos em um pensamento dual, prescritivo ou mesmo salvacionista e romântico, para pensar as linhas de força que vêm nos produzindo, os jogos de verdade e os modos de subjetivação. Assim, as metanarrativas são desnaturalizadas, optando-se por uma pesquisa das forças em vez das essências.

Neste artigo, escolhemos fazer uma aliança com o pensamento da diferença, que é sempre múltiplo, tomando um conceito em específico para o atravessarmos com as discussões na educação. Trata-se do conceito de montagem, o qual tentamos operar nas brechas dos clichês, a partir dos estudos de dois autores: Gilles Deleuze e Georges Didi-Huberman, tomando-os para pensar na potência da montagem do pensamento e da escrita acadêmica em educação.

A montagem, para esta pesquisa, tem um uso potente no deslocamento do campo das artes - principalmente do cinema e do teatro -, bem como da filosofia, para o campo da educação, como uma ideia em suspensão, como uma bela inquietação do pensamento para operar com a escrita textual. A partir disso, tomamos a montagem como gesto político, artístico, filosófico e ético de desmontar, desnaturalizar o olhar, diagnosticar os sintomas do presente e produzir outras composições possíveis. Se, a partir de autores como Nietzsche (1983), Foucault (2002) e Deleuze (2006), a relação entre as palavras e as coisas são problematizadas, assim como o suposto lugar comum em que elas se encontrariam, a relação representacional com o pensamento pode ser deslocada com a diferença. Desse modo, a montagem induz a um novo estilo de saber, a novos procedimentos de lidação com o que temos por realidade, "logo, a novos conteúdos de saber, no âmbito de uma concepção original e, por assim dizer, subversiva do tempo histórico" (DIDI-HUBERMAN, 2015b, p. 52).

O texto arranja-se trazendo o conceito de montagem operado por Deleuze a partir do cinema. Do mesmo modo, trazemos o conceito de montagem em Didi-Huberman por meio de um rastreamento desse conceito em sua obra, operado como procedimento

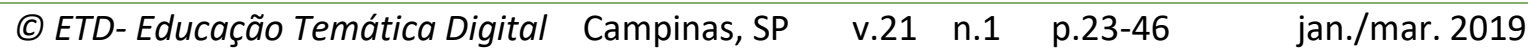


filosófico, gesto político e criação artística. Tal como um belo tormento, esse conceito poderia funcionar para pensarmos a diferença em educação, especialmente tomando a escrita acadêmica.

\section{CONCEITO DE MONTAGEM EM GILLES DELEUZE}

Traçamos aqui algumas considerações de Deleuze ao operar com a imagemmovimento no curso sobre o cinema, nas suas primeiras aulas de 1981 , ao falar sobre as três teses de Bergson e os três níveis da imagem-movimento e o cinema. Utilizam-se aqui os cursos ministrados por Deleuze na Universidade de Paris 8, que deram origem aos livros Imagem-Movimento e Imagem-Tempo. Cabe dizer que o primeiro contato com o termo montagem se deu nessas obras sobre o estudo do cinema por Deleuze.

Para o autor, o mundo em que vivemos é um mundo de mesclas, onde tudo está em movimento de composição e a experiência se dá na soma dos estilhaços que vivemos. Em suas palavras, "el mundo en el cual vivimos es un mundo de mezclas, las cosas están siempre mezcladas, todo se mezcla. En la experiencia no hay más que... cómo diríamos?...mixtos. Hay mezclas de esto y de aquello. Lo que les es dado son estas mezclas" (DELEUZE, 2009, p. 21).

Para Deleuze (2009, p. 24-39), a fórmula do cinema é uma sucessão de instantes em imagens equidistantes, e essa distância das imagens é o que permite a uniformidade do tempo. Se nossa vivência, e pensamos aqui na vivência e experiência da escrita acadêmica e do pensamento em educação, se organiza na composição das mesclas, dos estilhaços e fragmentos, nós nos montamos a partir desses intervalos. O movimento acontece nos intervalos, ou seja, o movimento é uma sucessão de cortes móveis no tempo.

Deleuze comenta que existem duas maneiras de pensar o movimento, uma "forma antiga" e outra "moderna". A forma antiga pensa o movimento como algo eterno e imóvel: "o movimento assim concebido será, portanto, a passagem reguladora de uma forma a outra, isto é, uma ordem de poses ou de instantes privilegiados" (DELEUZE, 1985, p. 12). Ele acrescenta que o pensamento moderno "consistiu em referir o movimento não mais a instantes privilegiados, mas a instantes quaisquer". O movimento acontece a partir de cortes, por momentos equidistantes - "el movimiento debe ser definido en función de un instante cualquiera" (DELEUZE, 2009, p. 32).

Os Instantes Quaisquer rompem com os momentos privilegiados, existindo no entre, entre uma imagem e outra. Lembramos que não é um pensamento dualista - ou é isso, ou é aquilo -, mas sim um pensamento do entre, do isso e aquilo e aquilo outro. É o método do entre, "entre duas ações, entre duas afecções, entre duas percepções, entre duas imagens visuais, entre duas imagens sonoras, entre o sonoro e o visual: fazer ver o indiscernível, quer

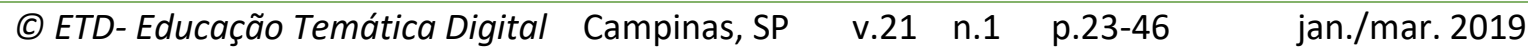


dizer, a fronteira" (DELEUZE, 2007, p. 217). O instante qualquer, que rompe, que faz brecha, que provoca o entre, que faz intervalo, é o que possibilita a montagem. Nesse movimento de instantes quaisquer, somos capazes de pensar a produção do novo.

Deleuze (2009) pergunta-se: mas o que quer dizer um instante qualquer? Para ele, o instante qualquer é uma relação, uma relação entre os instantes. $O$ instante qualquer é um instante indeterminado que é determinado pelo intervalo de distância entre dois instantes equidistantes. O que define o cinema, para Deleuze (2009), é a relação que o movimento faz com os instantes quaisquer. Poder-se-ia dizer que a aproximação desses instantes quaisquer acontece pela montagem e, com isso, dizer que o cinema acontece na montagem. Cabe aqui uma nota que nos ajuda a pensar. A palavra qualquer, no português, é a única cujo plural acontece no meio - e o que acontece no meio é o entre.

Não nos interessa aqui um aprofundamento sobre a teoria da montagem no cinema, mas tomar como Deleuze realiza a escrita desse pensamento nos dois cursos citados, que dão origem a Imagem-Movimento e Imagem-Tempo. Mostra-se importante, então, a seguinte diferenciação nos estudos de Deleuze sobre o cinema, sendo que ele descreve três níveis para distinguir a imagem-movimento: 1) o enquadramento, 2) o plano e 3) a montagem. Em termos técnicos: 1) o conteúdo da imagem é o que está relacionado com o enquadramento; 2) a imagem é a captação do plano; e 3) a ideia do filme se realiza com a montagem.

A partir disso, podemos pensar em três movimentos importantes, ajudados por Deleuze: 1) somos compostos de estilhaços de mesclas de coisas; 2) isso acontece no intervalo de tempo; 3) e o tempo é a soma de imagens equidistantes, dos instantes quaisquer - "escolhidos de modo a dar a impressão de continuidade" (DELEUZE, 1985, p. 13). Ou seja, três movimentos agenciando a montagem como pensamento.

Para Deleuze (1985; 2009), analisando as teorias do cinema, existem algumas ferramentas da montagem que seriam os raccords, os cortes e os falsos raccords. O raccord é a continuidade da imagem cinematográfica, ou seja, a relação entre os planos que montam uma narrativa dando a ideia de sequência, as continuidades do vestuário, da maquiagem, do cenário, etc. O falso raccord são as mudanças que acontecem, descontinuando o plano anterior, um salto de cena, de tempo ou de situação. Os cortes são o que separa uma imagem da outra, um instante do outro.

$\mathrm{Na}$ montagem do pensamento e da escrita em educação, podemos dizer que os estilhaços são as palavras que se mesclam, se juntam, possibilitando a escrita do texto. 0 que acontece no intervalo de uma palavra e outra, no tempo da escrita e da leitura, seria o pensamento? E o que acontece nos encontros com a música, com a literatura, com um

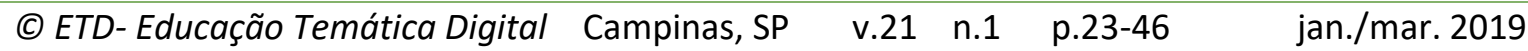


texto, com uma imagem, com colegas, com professores, com grupos de pesquisa, em se tratando da escrita acadêmica em educação?

\section{O CONCEITO DE MONTAGEM EM GEORGES DIDI-HUBERMAN}

Mas por que tal interesse pela montagem? Como comentado anteriormente, a aproximação com o conceito deu-se com as obras sobre o cinema de Deleuze e ao iniciar-se o estudo do pensamento de Georges Didi-Huberman. Didi-Huberman utiliza uma constelação de teóricos na operação do seu pensamento, como: Waburg, Benjamin, Freud, Lacan, Foucault, Deleuze. Muitos referenciais do campo da literatura: Baudelaire, Proust, Joyce, Bataille, Beckett, Kafka. Outros do campo das artes, como: Fra Angelico, Botticelli, Marey, Brecht, Giacometti, Pasolini, Turrell, Harun Farocki, Judd e Morris. Opera em uma montagem de saberes da história, psicanálise e filosofia, entre outros. Didi-Huberman tem influenciado o pensamento sobre a História da Arte e a Antropologia Visual, estando fortemente presente nos estudos das imagens ou, como se chama atualmente, Filosofia da Imagem (ALMEIDA, 2015).

A produção de Didi-Huberman tem sido marcada pelo pensar com imagens, colocando-as em relação (ALMEIDA, 2015). Ele trabalha pensando as imagens como um processo e um ato, e também como uma forma de ação política (JACQUES, 2015). DidiHuberman desenvolve o conceito de montagem em toda sua obra, em suas aulas, palestras, textos e livros. Realizamos, pois, um mapeamento de onde Didi-Huberman opera com o conceito de montagem em suas obras.

Em Ce que nous voyons, ce qui nous regard (DIDI-HUBERMAN, 1992) - O que vemos e o que nos olha (DIDI-HUBERMAN, 2010) -, o conceito é trabalhado como um momento singular de pensamento e do ato de ver, trabalhando com as obras do artista Tony Smith. Este livro é escrito a partir de duas conferências realizadas no ano de 1991 e publicadas em três artigos diferentes no mesmo ano.

Didi-Huberman trabalha com a montagem a partir da Revue Documents, produzida nos anos de 1929 e 1930, que teve 15 edições, no livro La Ressemblance informe, ou le gai savoir visuel selon Georges Bataille (DIDI-HUBERMAN, 1995) - A Semelhança informe: ou o gaio saber visual segundo Georges Bataille (2015a). Além de Bataille, a Revue Documents também teve na linha de frente Carl Einstein, que no seu curto período marcou o mundo da arte pela proposta ousada de compor esteticamente a palavra e a imagem por meio da montagem. Didi-Huberman debruça-se na questão da semelhança nesse livro, sendo que algumas partes da obra foram apresentadas em 1993 em um seminário dedicado a Georges Bataille, e outros fragmentos em uma série de seminários na École de Hautes Études en Sciences Sociales (EHESS). Alguns extratos foram publicados no ano de 1994.
(c) ETD-Educação Temática Digital
Campinas, SP
v.21 $\quad$ n.1 p.23-46
jan./mar. 2019 
Encontramos um uso maior do conceito no livro Devant le temps. Histoire de l'art et anachronisme des images (2000) - Diante do Tempo: História da arte e anacronismo das imagens (2015b) -, sobretudo na primeira parte, intitulada 'Arqueologia do Anacronismo', pensando a montagem como anacronismo, em seus tempos heterogêneos, como um corte no pensamento, e colocando a imagem no centro do pensamento, relacionada com o tempo. Nesse livro, o autor apresenta as fontes onde busca o conceito de montagem, dissertando principalmente sobre Walter Benjamin, Carl Einstein e Aby Warburg. O texto desse livro é composto de partes de um seminário apresentado na EHESS entre 1994 e 1995, tendo sido publicadas em alemão e francês nos anos de 1995 e 1996. Outra parte do texto foi apresentada em 1999 em um colóquio sobre o pensamento de Walter Benjamin, sendo publicada em 2000.

Alguns anos após Devant le temps, Didi-Huberman, concentra seu estudo e sua pesquisa em Aby Warburg. Inicialmente, o livro foi pensado em 1990 como uma continuação do livro Devant l'image (1990) em seminários na EHESS entre os anos de 1990 e1992, o que resultou em uma série de artigos publicados entre os anos de 1992 e 1998. O livro foi publicado em 2002, L'Image survivante. Histoire de l'art et temps des fantômes selon Aby Warburg (2002) - A imagem sobrevivente: História da arte e tempo dos fantasmas segundo Aby Warburg (2013a). Didi-Huberman trabalha sobre o conceito de Nachleben (sobrevivência) e o Atlas Mnemosyne de Warburg. Percebem-se, nesse livro, a montagem imagética produzida no Atlas e a forma de trabalhar com o conceito que rompe com a simples aproximação de imagens, mas que marca as sobrevivências e uma forma de pensamento que permite desterritorializar os objetos de conhecimento. Alguns textos estão espalhados em revistas de 1998 a 2001.

Didi-Huberman utiliza-se do conceito de montagem para pensar as quatro imagens registradas por prisioneiros do campo de concentração de Auschwitz-Birkenau, trabalhando com a imagem como um registro, um testemunho e uma sobrevivência, apesar de tudo, no livro, Images malgré tout (2003) - Imagens apesar de tudo (2012a). A montagem é utilizada para pensar nas singularidades e nas multiplicidades do tempo, sendo ela uma forma de organizar o ver que não dá a ver o todo, ou seja, montagem como o que se mostra, como o que faz ver. A primeira parte do livro é escrita em 2000 para publicação no catálogo da Memória dos campos de concentração. A segunda parte, onde aparece com mais força o conceito de montagem, faz parte de uma série de seminários no início de 2003 em Berlim.

Podemos perceber que, de 1992 até 2003, o conceito de montagem vem acompanhando algumas de suas publicações, sendo utilizado pela margem, como um modo de pensar determinadas questões. Tal discussão também é operada de diferentes formas nos livros dos anos seguintes, de 2004 a 2008: Mouvements de l'air. Étienne-Jules Marey,

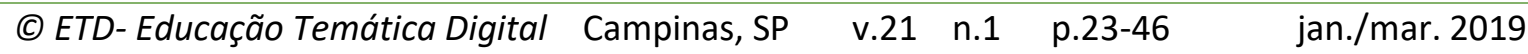


photografe des fluides, avec Laurent Mannoni (2004); Gestes d'air et de pierre. Corps, parole, souffle, image (2005); Ex-voto. Image, organe, temps (2006); Le Danseur des solitudes (2006); L'image ouverte. Motifs de l'incarnation dans les arts visuels (2007) e La Ressemblance par contact. Archéologie, anachronisme et modernité de l'empreinte (2008).

Nos últimos anos, de 2009 a 2016, Didi-Huberman tem se dedicado com mais força ao conceito de montagem, sendo um dos principais temas do seu pensamento na coleção L'CEil de l'histoire: Quand les images prennent position (2009); Remontages du temps subi (2010); Atlas ou le gai savoir inquiet (2011); Peuples exposés, peuples figurants (2012); Passés cités par JLG (2015) e Peuples en larmes, peuples en armes (2016).

O primeiro livro dessa coleção é dedicado ao pensamento de Bertold Brecht. A montagem aparece como método de conhecimento e procedimento formal nos livros Diário de Trabalho e $A B C$ da Guerra, onde Brecht trabalha suas anotações fragmentárias e suas imagens como uma técnica de montagem. Aqui temos uma concepção de montagem como montagem das diferenças. O livro, de Didi-Huberman, Quand les images prennent position (2009) foi recentemente traduzido para o português como Quando as imagens tomam posição (2017), sendo que a tradução em espanhol chama-se Cuando las imágenes toman posición (2013d).

L'CEil de l'histoire: Remontages du temps subi (2010), analisa certos pensadores e artistas que trabalham por montagem; um deles é Christian Boltanski, e outro é Harun Farocki. Nesse livro, Didi-Huberman trabalha com o cinema, a fotografia e as artes visuais. No terceiro volume, Atlas ou le gai savoir inquiet (2011) - com tradução para o português de Portugal, Atlas ou a Gaia Ciência Inquieta (2013b) -, trabalha com o pensamento de Aby Warburg. Peuples exposés, peuples figurants (2012) é uma reflexão sobre as maneiras como as pessoas são concebidas atualmente, sendo que aqui Didi-Huberman traz algumas questões da estética e da política. Um dos artistas que o autor trabalha nesse livro é Pasolini. O quinto volume, Passés cités par JLG (2015), é uma imersão nas obras do cineasta Jean-Luc Godard, e Peuples en larmes, peuples en armes (2016), também apostando nas discussões políticas, trabalha com imagens dos filmes de Serguei Eisentein, como, por exemplo, O Encouraçado Potemkin.

Realiza-se esse apanhado biográfico para que se possa perceber que a questão da montagem no pensamento de Didi-Huberman vem se constituindo pela margem desde 1992, intensificando-se nos últimos livros que compõem O Olho da História. Trata-se de uma produção de pensamento que o acompanha nos últimos 24 anos, em que a palavratermo-ideia-conceito montagem atravessa o pensamento e a escrita. A escrita dos livros, que muitas vezes derivam de aulas e seminários, é um exercício de pensamento em movimento.
(C) ETD- Educação Temática Digita
Campinas, SP
$\begin{array}{lll}\text { v.21 n.1 p.23-46 } & \end{array}$
jan./mar. 2019 
Didi-Huberman opera com o conceito de montagem realizando estudos e pesquisas, principalmente, do Atlas-Mnenosyne de Aby Warburg; dos escritos fragmentários, do colecionismo e da montagem literária em Walter Benjamin, sobretudo no seu livro Passagens; do trabalho de edição e montagem de repulsas da Revue Documents de Bataille; dos textos e das colagens de Brecht, em Diário de Trabalho e ABC da Guerra; e do movimento imagético e montagem das atrações proporcionados no cinema por Eisenstein e Godard. Esses autores "revelaram, entre outros exemplos, a fecundidade de um tal conhecimento através da montagem: conhecimento delicado - como tudo o que diz respeito às imagens - simultaneamente repleto de armadilhas e pejado de tesouros" (DIDIHUBERMAN, 2012a, p. 155).

Podemos encontrar formas de pensar por montagem em Aby Waburg, March Broch, Walter Benjamin, Sergei Eisenstein, Carl Eisntein, André Marlaux, George Bataille, George Simmel, Franz Kafka, Marcel Proust e Igor Stravisnky, autores que, para Didi-Huberman (2007, p. 2), operam com um verdadeiro pensamento por montagem: "así lo llamo yo conocimiento por el montaje". A partir disso, na leitura que realizamos da extensa produção de Didi-Huberman, podemos pensar a montagem enquanto procedimento filosófico, gesto político e criação artística, dimensões não segmentadas ou hierarquizadas, mas que se entrecruzam na produção de um pensamento diferencial.

\section{Procedimento Filosófico}

A montagem como procedimento filosófico coloca em funcionamento uma forma que permite pensar a diferença. Por isso, a montagem não pode ser tomada como simples arranjamento de algo, mas está implicada na produção da diferença. Desse modo, ela é esse deslocamento de um espaço para outro, de uma temporalidade para outra. Um anacronismo. Para o autor, a montagem é um método, um procedimento moderno de conhecimento.

\footnotetext{
O conhecimento pela montagem foi uma resposta das vanguardas modernas aos excessos da própria modernidade, de sua cientificidade "positivista", uma resposta contra os diferentes fechamentos metodológicos funcionalistas do positivismo mas também contra os formalismos estetizantes, ambos ainda dominantes em diferentes campos disciplinares. (JACQUES, 2015, p. 69-70).
}

Em uma entrevista de 2007, ao falar sobre a imagem, Didi-Huberman (2007, s.p) comenta que a imagem é o que dura apenas um instante, um instante momentâneo, um instante qualquer - "Eso es la imagen. La imagen es una mariposa. Una imagen es algo que vive y que sólo nos muestra su capacidad de verdad en un destello". E, como observamos em Deleuze, o instante qualquer é o que conecta a imagem, ou seja, uma montagem.
(C) ETD- Educação Temática Digital
Campinas, SP
v.21 n.1 p.23-46
jan./mar. 2019 
Em Imagens apesar de tudo, Didi-Huberman (2012a, p. 156) trabalha com a noção de montagem como abertura, como diferença e diferenciação, quando cria uma cisão no que está reunido e conecta o que está separado. A montagem opera por nexos de sentidos que aproximam as imagens para produzir outra imagem, ou uma questão. A montagem faz pensar, faz ver, torna possíveis as diferenças, dá a ver outra possibilidade de conhecimento. Isso fica claro quando o autor diz que a montagem oferece "singularidades múltiplas, susceptíveis de diferentes, ou de diferenças".

\begin{abstract}
A montagem é uma exposição de anacronismos naquilo mesmo que ela procede como uma explosão da cronologia. A montagem talha as coisas habitualmente reunidas e conecta as coisas habitualmente separadas. Ela cria, portanto, um abalo e um movimento: $\mathrm{O}$ abalo. Estamos fora de nós. $\mathrm{O}$ olhar vacila e, com ele, aquilo que ele fixava. As coisas exteriores não são mais familiares, elas se deslocam. Qualquer coisa ali se tornou muito leve, que vai e vem. (DIDI-HUBERMAN, 2016, p. 6).
\end{abstract}

Em Diante do Tempo, Didi-Huberman (2015b) cita Benjamin para falar do processo de montagem enquanto método e forma de conhecimento. Diz que o historiador remonta os "restos", esses fragmentos históricos que conectam sentidos, porque se faz necessário para entender e conhecer "a dupla capacidade de desmontar a história e de montar junto os tempos heterogêneos, Outrora como Agora, sobrevivências com sintomas, latências com crises...". Ou seja, "não se pode jamais separar o objeto de um conhecimento e seu método - ou seja, seu estilo" (DIDI-HUBERMAN, 2015b, p. 133).

No processo de montagem, utilizam-se os restos, o que sobra, os farrapos e resíduos desses fragmentos diferentes, heterogêneos, que conectam e criam outra coisa, sempre em um processo que necessita desmontagem - remontagem - montagem, mas que não é a síntese dialética. Para que a montagem seja pensada como método e forma de conhecimento, é necessário utilizar-se o procedimento de desmontagem e montagem. Montagem entendida, dessa forma, como uma aproximação e uma transgressão das fronteiras disciplinares (JACQUES, 2015), pensando com isso o que é diferencial.

Assim, para Didi-Huberman (2014), a montagem significa uma renúncia à totalização unificadora e imobilização temporal, optando por tempos e espaços heterogêneos que se confrontam, se cruzam e abrem sempre para a criação de outras configurações. Por isso, poderíamos tomar nossas teses, dissertações, artigos, capítulos de livro, como tábuas de montagem, funcionando como um aparelho concreto de pensamento, o que exige sempre uma leitura recomeçada para sacudir as familiaridades dos nossos modos de pensar a educação.

A partir da problematização arqueológica de Foucault, Didi-Huberman (2014) problematiza esse lugar do "quadro", tal como esse espaço comum onde se opera com os seres de modo ordenado, onde se encontraria o nexo entre as palavras e as coisas. Para

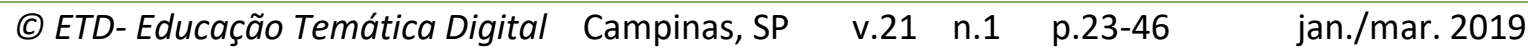


esburacar essa história do mesmo, o autor traz a possibilidade da tábua como esse trabalho sempre por fazer que resiste ao emparedamento do humano. Isso transforma o conhecimento em seu suporte, modo de exposição e disposição, o que arrasta também seu conteúdo. Nessa lidação com um pensamento mais inventivo,

Escrever - que se trate de Ficciones ou de crônicas, de poemas ou de ensaios documentários - consistiria, pois, sob esse ângulo, em formar um atlas ou a cartografia desorientadora de nossas experiências incomensuráveis (o que é muito diferente de fazer o relato ou o catálogo de nossas experiências comensuráveis. (DIDI-HUBERMAN, 2014, p. 244).

\section{Gesto Político}

Justamente nessa perspectiva, não de forma excludente, mas como uma composição, podemos tomar a montagem também como um gesto político, tal como um belo tormento. $\mathrm{O}$ autor realiza um exercício de pensamento por imagens, de aproximação, ou seja, de montagem de um pensamento com as imagens, um exercício de pensamento por montagem. Mas montagem não é uma simples composição, uma simples aproximação.

Em Diante do tempo, Didi-Huberman (2015b, p. 123) traz, pensando com Benjamin, que o historiador "vive sobre um monte de trapos: é o erudito das impurezas, dos restos da história. É o arqueólogo do inconsciente da história". O historiador é um trapeiro, "mas também uma criança que, como bem se sabe, utiliza qualquer dejeto para constituir uma nova coleção" (Ibidem., p. 119). Podemos pensar os restos como fragmentos que podem ser utilizados de diferentes formas e o historiador como aquele que está olhando para esse conjunto, mas utilizando um olhar de montador, que ao olhar o todo desmonta para depois remontar.

Didi-Huberman, citando Benjamin, vai dizer que "este trabalho deve desenvolver ao mais alto grau a arte de citar sem aspas. A teoria dessa arte está em correlação estreita com a da montagem" (BENJAMIN, 2009, p. 500); Benjamin continua:

\footnotetext{
o método desse trabalho: a montagem literária. Não tenho nada a dizer. Somente mostrar. Não vou roubar nada de precioso nem me apropriar das fórmulas espirituosas. Mas sim, dos arranjos, dos restos: não quero fazer o inventário disso, mas permitir-lhes obter justiça da única maneira possível: utilizando-os (BENJAMIN, 2009, p.502).
}

A montagem é operada como uma utilização de restos, de fragmentos, criando e dando condição a uma legibilidade dos restos, ou desses pequenos fragmentos que estilhaçam o pensamento e montam outro. A montagem torna visíveis - dá a ver outras possibilidades - o pensamento e uma escrita como uma real modificação, "para além dos puros aglomerados, aquém de toda síntese, o conhecimento por montagem faz pensar o
(C) ETD- Educação Temática Digital
Campinas, SP
$\begin{array}{lll}\text { v.21 n.1 p.23-46 } & \end{array}$
jan./mar. 2019 
real como uma modificação" (DIDI-HUBERMAN, 2015b, p. 156). Um efeito de estranheza que permite a singularização e um acesso a novas formas de observar as coisas.

A desmontagem é um movimento de sintomatologização, de interrogação da própria historicidade para pensar que imagens se estão produzindo, mas também movimentos éticos, estéticos e políticos de montagem de outras possibilidades. A montagem é a produção do novo, de um pensamento da criação (DELEUZE, 2009). Para montar, necessita-se primeiro desmontar. Para montar, é preciso repetir. Juntar imagens que inventem outras e novas relações, arriscar, fracassar. Isso é o que permitiria a união e a comunicação da diferença.

Desmontar é realizar um procedimento como a máquina de Elida Tessler; ao fazer-se isso, tem-se a possibilidade de modificar a sua configuração. Podemos criar pilhas, montes, constelações; podemos abrir novas analogias, novos trajetos no pensamento. Ao cortarmos o pensamento, ao fragmentarmos a escrita, ao colocarmo-nos na experiência de montá-los, podemos observar melhor os sintomas do presente e abrir frestas e possibilidades de pensar e escrever diferentemente em educação. "É de fato de montagem ou de remontagem que se deve falar, pois, enquanto procedimento, a montagem supõe a desmontagem" (DIDI-HUBERMAN, 2015b, p. 132).

E qual a força política de não se pensar mais o mesmo e se apostar em funcionamentos por montagem? Didi-Huberman (2015b, p. 131) dirá que "uma imagem que me desmonta, é uma imagem que me interrompe, me interpela, uma imagem que me deixa confuso, privando-me momentaneamente de meus recursos, faz-me perder o chão". A desmontagem seria um gesto político de dar a ver outras possibilidades, dessa forma, desmontar para ver melhor os sintomas do presente. Trata-se de outra relação com a tradição - mas ainda se trata dessa relação.

\section{Criação artística}

Desmontar mostra uma descontinuidade, e, como procedimento, a montagem supõe a desmontagem. Para criar a obra "Carta ao Pai", Elida Tessler teve que desmontar, criar fragmentos, sendo que podemos entender, dessa forma, a montagem como criação artística, intrinsecamente ligada ao gesto político, algo que faz pensar, ou seja, como procedimento filosófico. Para Didi-Huberman (2013d, p. 102), a arte mostra a força política, expondo em um duplo sentido, "en el doble sentido del término - argumento de discurso y disposición de imágenes [...] El arte según Brecht desmonta y vuelve a montar la historia para mostrar su tenor político".

A arte decompõe a ordem das coisas, "hace surgir y adjunta esas formas heterogéneas ignorando todo orden de grandeza, toda jerarquía, es decir, proyectándolas en el mismo plano de proximidad" (Ibidem, p. 78). A criança, quando aprende a ler, realiza um processo de montagem, desmontagem, remontagem da palavra lida e escrita, em um
(C) ETD- Educação Temática Digital
Campinas, SP
v.21 n.1
p.23-46
jan./mar. 2019 
procedimento de conhecimento para ver como a palavra escrita e falada funciona, assim como

[...] se desmonta um relógio, ou seja, como se disjunta minuciosamente as peças de um mecanismo. Enquanto isso, o relógio para de funcionar, é claro. Entretanto essa parada - die Dialektik im Stillstand - provoca um efeito de conhecimento que, de outra forma, seria impossível. Pode-se desmontar as peças de um relógio para aniquilar com o insuportável tiquetaque da contagem do tempo, mas também para entender melhor como funciona, e até mesmo para consertar o relógio defeituoso. Esse é o duplo regime descrito pelo verbo desmontar: de um lado, a queda turbilhonante, de outro, o discernimento, a desconstrução estrutural (DIDI-HUBERMAN, 2015b, p. 131).

Por isso, trata-se sempre de uma questão política, de lampejos, de uma micropolítica dos vagalumes. Didi-Huberman (2011) trabalha com a ideia de lampejos, de palavraslampejo e imagens-vagalumes no seu livro A sobrevivência dos vagalumes. É uma imagem de pensamento que fala de pequenas luzes como vagalumes. A imagem não é dele, mas sim de Pasolini, ao escrever em 1941 uma carta a um amigo de infância. Nessa carta, Pasolini diz ver pequenos pontos brilhantes a dançar no escuro do tempo, uma dança dos vagalumes.

Em 1941, Pasolini fala do aparecimento dos vagalumes, de um processo de experiência que potencializa as vidas, mas, em 1975, 34 anos depois do aparecimento dos vagalumes, Pasolini escreve outra carta, falando do desaparecimento deles: "os vagalumes desapareceram, esses sinais humanos da inocência aniquilados pela noite - ou pela luz feroz dos projetores - do fascismo triunfante" (DIDI-HUBERMAN, 2011, p. 26). Pasolini fala da situação política da Itália, depois de vencido o fascismo nos anos 30 e 40. Depois de pensar que o autoritarismo e o fascismo estariam mortos, se depara com o aleta de Foucault sobre "o amor pelo poder" e sobre os microfacismos que nos habitam.

Os vagalumes desapareceram na ofuscante claridade dos ferozes projetores... desapareceram nessa época de ditadura industrial e consumista em que cada um acaba se exibindo como se fosse uma mercadoria em sua vitrine, uma forma justamente de não aparecer (DIDI-HUBERMAN, 2011, p. 30-38).

Pasolini, ao falar desse desaparecimento dos vagalumes, fala do declínio da experiência no contemporâneo, o que nos leva a pensar o quanto de vida há no que pensamos e escrevemos em educação. O que nos faz pensar nos fascismos que arrastamos em nossas produções e modos de vida. O que nos faz pensar em nossas patrulhas morais. A questão da política é central no texto de Didi-Huberman, assim como para este texto, o qual quer pensar em pequenos pontos de luzes, no escuro de nosso tempo, para novas possibilidades de pensar a escrita acadêmica. Porém, não se trata aqui de uma iluminação nos moldes iluministas. Trata-se de uma micropolítica do texto. Uma micropolítica da escrita. Uma micropolítica dos lampejos e dos vagalumes.

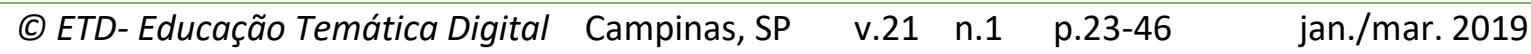


A montagem é um procedimento, uma criação, que permite um processo de interrupção, sendo possível sobrepor partes distintas. Didi-Huberman utiliza a montagem como um deslocamento, como uma descontinuidade no tempo e no pensamento. Mas, para isso, é necessário desmontar, ou seja, o procedimento de montagem inicia com o desmontar a ordem; criam-se, assim, intervalos, e deixa-se em suspenso, possibilitando ver as latências e lampejos deslocando sentidos de lugares. Depois, remonta-se, podendo-se dar a mesma ordem de antes, ou remontando outras configurações possíveis. Nessa remontagem, podemos ter outra imagem de pensamento, outro texto, outra montagem de sentidos.

A montagem é uma "decantação do tempo" (DIDI-HUBERMAN, 2015b), uma forma de pensar o mundo criando algo diferente, como um ato de compreensão pedagógica, como montagem dos sintomas do presente. A montagem produz um choque entre as imagens, fazendo que se produza outra, outro intervalo de tempo e outros instantes quaisquer "Para hacer un montaje tiene que haber un choque entre dos imágenes y, generalmente, de este choque surge una tercera" (Idem, 2007, p. 2). Assim, podemos pensar que a montagem atua na perspectiva dos sentidos, e não na dos significados, justamente porque não opera no mundo duplicado da representação.

Na montagem, não existe uma ordem a priori, ou uma lei de composição e de organização; monta-se a partir do acontecimento, das composições (DELEUZE, 1985). É uma colisão, e não uma justaposição (DELEUZE, 2009) no intervalo dos instantes, na produção de encontros e de distanciamentos, na associação e dissociação. E, para montar, é preciso repetir, conversar com a tradição. Com as tradições. Juntar imagens que inventem outras e novas composições.

\begin{abstract}
O processo de montagem compõe diferentes constelações, trata-se de uma forma complexa e generalista de conhecimento, uma compreensão sinóptica que cruza diferentes campos e disciplinas, e que não pode ser engessada como uma simples metodologia operacional. O importante não seria qualquer tipo de resultado final, fixo, mas sim o próprio processo aberto, uma renúncia do fixar. A partir dos diferentes intervalos - entre as diferentes remontagens de um mesmo painel, entre as montagens de diferentes painéis e, também, entre as imagens de cada montagem podem surgir outros nexos, a partir de associações, choques ou tensões entre as imagens, podem surgir relações inesperadas, outras constelações imprevistas, provocando uma série de inversões, rupturas, descontinuidades, emergências, anacronismos e sobrevivências (Nachleben). (JACQUES, 2015, p. 69-70).
\end{abstract}

Didi-Huberman trabalha a montagem como procedimento de remontagem, que se ocupa dos trapos, dos pormenores que dão legibilidade a um conjunto de pensamento que desloca e inquieta a vida. Montamos o pensamento colando nossas coleções de palavras (lidas, ouvidas, tomadas, pensadas, traduzidas). Somos montados por discursos que nos

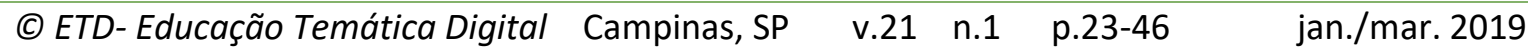


atravessam, certo anacronismo das palavras e do pensamento. A montagem é uma forma de pensar como procedimento que busca "formas mais complexas de ver, aprender a realidade" e como método do conhecimento "como método de criação, problematização o exposição de ideias" (JACQUES, 2015, p. 48).

Pensa-se, assim, a montagem como criação artística, como uma ruptura, uma possibilidade de pensar diferente sempre agenciada com um gesto político, "es un work in progress permanente, es working progress de la reflexión y de la imaginación, de la búsqueda y del hallazgo, de la escritura y de la imagen" (DIDI-HUBERMAN, 2013d, p. 19). O pensar diferencial, com a montagem, cria pequenas rupturas no sistema do pensamento e da escrita acadêmica, pequenas brechas, e "no hay que temer las brechas [...] Por dichas brechas, se sacan a la luz esas razones opuestas" (Ibidem, p. 89), as micropolíticas dos vagalumes.

\section{MONTAGEM DO PENSAMENTO E DA ESCRITA EM EDUCACÃO}

A partir disso, retomamos o entendimento da montagem como forma de pensamento, como um método de conhecimento, perpassando o procedimento filosófico, gesto político e criação artística. O conhecimento por montagem parte das diferenças, da conexão de fragmentos, de intervalos e instantes quaisquer, sem buscar a totalidade, a universalidade, a unidade. Separa o que está reunido e conecta o que está habitualmente separado (JACQUES, 2015). A ideia de montagem não parte de "ideias já dadas, de nexos prontos, ao contrário, busca encontrar possíveis nexos ainda não conhecidos durante a própria prática (exercício ou jogo) da montagem" (Ibidem, p. 69).

Entendemos, com Didi-Huberman (2013d, 2015b), que a montagem se debruça para olhar como se dá a relação entre as coisas. Esse procedimento funciona desnaturalizando o olhar para operar com o conhecimento por desmontagem e remontagem, problematizando a perspectiva da representação e do sujeito. Para o autor, a montagem é a arte de produzir esta forma que pensa a diferença. Montagem, então, como uma aproximação e uma transgressão das fronteiras disciplinares.

Essa diferenciação da montagem pode ser entendida como um processo de singularização, ou seja, uma "montagem das singularidades". No processo de montagem da escrita acadêmica e do pensamento em educação, lidamos com singularidades - do texto, do autor, do escritor, do leitor. A montagem de um texto realiza-se com escolhas dos fragmentos, das miudezas, dos pormenores de pensamento, das singularidades, mas também atravessada pelas políticas editoriais, pelos prazos institucionais, pelas regras acadêmicas.
(C) ETD- Educação Temática Digital
Campinas, SP
v.21 n.1 p.23-46
jan./mar. 2019 
Cabe lembrar que a montagem não apressa a conclusão de nada, nem fecha ou enclausura. A montagem abre as possibilidades e não as "esquematiza abusivamente. Quando nos permite aceder às singularidades do tempo e, por conseguinte, à sua multiplicidade essencial" (DIDI-HUBERMAN, 2012a, 156). A montagem, assim, pode ser tomada como uma escuta flutuante, atenta às redes de detalhes, às tramas sensíveis formadas pelas relações entre as coisas, os trapos, restos e fragmentos.

Almeida (2016, p. 34) faz um alerta importante sobre o uso do conhecimento por montagem na operação com a imagem, lembrando que não é um método a ser reproduzido, "menos ainda o autor sugere ou incentiva que se impute aos seus procedimentos qualquer universalidade num sentido metodológico estrito". Ou seja, não é uma fórmula, mas "uma postura, uma revisão de conceitos e processos e uma proposta de abordagem das imagens que não passa por constituir um conjunto de regras ou um modus operandi a partir do qual as imagens devem ser analisadas" (Ibidem, p. 34).

Como podemos perceber minimamente nesta escrita, Didi-Huberman opera com o pensamento por montagem como procedimento filosófico, gesto politico e criação artística e "talvez ele defenda tanto a montagem pois é - como de certa feita todos nós somos feito a partir dela. Todos somos montagens de imagens, textos, experiências" (CAMPOS, 2017, p. 287). Poderíamos, desse modo, nomear Georges Didi-Huberman como um Filósofo da Montagem.

A partir de tais discussões conceituais, podemos nos perguntar: existe uma montagem da escrita? Como ela sobrevive? Como existe e resiste? Como se dá a escrita como imagem e montagem do pensamento em educação? Como montar uma escrita? Como pensar a montagem em uma escrita acadêmica em educação? Podemos ver a montagem no campo do cinema e das imagens, mas como cartografar, ou narrar, a montagem do pensamento na escrita acadêmica em educação?

O conhecimento por montagem, no estudo de Didi-Huberman de Warburg, Benjamin, Bataille, Brech, Eisenstein e Godard, entre outros, propõe uma abertura, uma criação de algo novo no choque produzido pelas imagens e palavras. Dessa maneira, falar da escrita acadêmica e da montagem do pensamento em educação é ocupar-se dos fragmentos da escrita e do pensamento, dos restos, dos trapos.

Mas por que uma montagem? Em que a montagem difere de uma constituição epistêmica padrão? E por que pensar isso em educação? Didi-Huberman ajuda-nos a responder dizendo que a montagem dá a ver e não mostra algo, trabalha com um regime de legibilidade e tem como papel fundamental, no processo de conhecimento, estabelecer "ressonâncias ou diferenças com outras fontes, imagens ou testemunhos" (DIDIHUBERMAN, 2012a, p.155). Para o autor, o conhecimento está em movimento e não está

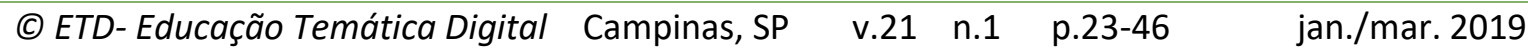


condicionado a uma única possibilidade, a uma única imagem. Assim, "trata-se, ao contrário, de pôr o múltiplo em movimento, de não isolar nada, de fazer surgir os hiatos e as analogias, as indeterminações e as sobredeterminações em jogo nas imagens" (Ibidem, p.155). Portanto, um deslocamento do pensamento reflexivo para um pensamento que coloca problemas.

A montagem difere por esse movimento de construção intermitente e pelo que ela dá a ver, o que torna legível. A montagem difere como forma de pensamento nãodogmático, para produzir uma forma a fim de tornar possível pensar a diferença. Assim,

[...] não é a montagem que, num filme, se encarrega da mostração das diferenças? Precisamos de montar o que não podemos ver, para, se possível, dar a pensar as diferenças entre algumas mómodas visuais separadas, lacunares - como uma forma de dar a conhecer apesar de tudo aquilo que é impossível ver inteiramente, aquilo que permanece inacessível como um todo (DIDI-HUBERMAN, 2012a, p. 176).

Para pensar outras possibilidades com a escrita acadêmica, talvez o conceito de montagem possa auxiliar-nos a produzir outros sentidos. Para tanto, a partir das discussões já realizadas, pode-se dizer que uma escrita por montagem em educação poderia funcionar a partir de algumas operações.

Uma primeira questão diria respeito ao funcionamento de desmontagem, ou seja, ficarmos atentos e atentas às forças que atravessam a escrita acadêmica, sejam elas as políticas dos Programas de Pós-Graduação, sejam as políticas editoriais, os financiamentos ou os prazos institucionais, entre tantas outras. Com isso, não se quer dizer que essas questões estão sendo denunciadas e devam ser abolidas; pelo contrário, trata-se, em um primeiro momento, de entender como funcionam, para, junto a isso, produzir outras composições possíveis.

Essa escrita por montagem também poderia perguntar pelas imagens de pensamento que estamos produzindo quando escrevemos dissertações, teses, capítulos de livros e artigos em educação e, a partir disso, tomar posição. Operar com a escrita por montagem pode significar tomar posição de renúncia à fixidez, buscando sintomatologizar, ao modo de Nietzsche (2006), os sintomas do presente, tomando esses restos da história para, por meio da escrita, juntar autores, conceitos, imagens, discussões, ideias, traços ainda não reunidos, ainda não arranjados dessa forma. Trata-se de pequenos deslocamentos, e não de uma grande revolução. Trata-se de uma micropolítica dos vagalumes. Trata-se de produzir outras legibilidades, tornar visíveis, dar a ver e pensar outras possibilidades em educação.

E, quando conectamos o não-habitual, não estamos produzindo outros sentidos? Quando problematizamos a lógica da representação com a verdade original e o sujeito

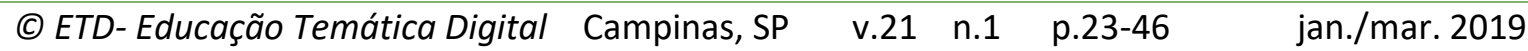


fundante na pesquisa e na escrita em educação, não estamos pensando de outros modos? E pensar de outros modos em educação não exigiria, necessariamente, ler e escrever de outras formas?

Assim, montar a escrita e o pensamento em educação poderia ser dar a ver a diferença em brechas. Didi-Huberman (2012a, p. 176) diz com as palavras de Godard que "a montagem, [...] é o que faz ver", é aquilo que transforma o visível e o legível, "é uma forma de a situar claramente à altura do pensamento". Ao montarmos o pensamento em uma escrita acadêmica na área da educação, seja ela em artigos, livros, teses, dissertações ou ensaios, estamos arranjando uma forma que pensa e que pode produzir efeitos em quem vai se encontrar com essa leitura. A questão aqui pautada é como pensar esse arranjamento por montagem para tornar possível não se pensar mais o mesmo, como um gesto ético, estético e político, nestes tempos contemporâneos de declínio da experiência.

E como pensar essa possibilidade em tempos em que a escrita acadêmica se dá em condições de possibilidade de hierarquizações, contagens e cálculos entre programas de pós-graduação, universidades, pesquisadores e alunos? Essa é uma condição que vem atravessando a escrita acadêmica. Além disso, podemos citar as parcerias nos grupos de pesquisa, as escritas compartilhadas com pares em eventos, em conversas, nas disciplinas acadêmicas, bem como em movimentos mais coletivos de escrita.

Somos subjetivados por um tipo de escrita e de arranjamento do pensamento em que a escrita é tomada majoritariamente em sua função explicativa, prescritiva, normativa e, por que não, moralista. Escrevemos em um tempo que valora a rapidez como virtude, a produção em massa de artigos, a novidade pela novidade, lendo e elegendo somente o que é útil para a pesquisa, lendo e escrevendo opinião, sem se descentrar de si, em que a ruminação necessária fica esvaziada de sentido. Escrevemos para pertencer, para pontuar, para mostrar habilidades e o valor profissional. Como traz Larrosa (2016), escrevemos a partir dos critérios que se supõem ser do avaliador. Mas como lê o avaliador? E aqui não se trata de uma denúncia da escrita acadêmica como vem funcionando, até porque é de dentro da academia que escrevemos, mas de um gesto político de produzir alguns esburacamentos, ao modo de Kafka (2009), para respirarmos minimamente outras coisas.

Trata-se muito mais de retomar a já conhecida fala de Foucault quando diz que a escrita pode ser perigosa, pode ser pensada como fogos de artifício, como coisas que fazem explodir. Por isso essa aposta em uma micropolítica dos vagalumes. Didi-Huberman (2011) traz que a questão dos vagalumes é política e histórica, porque pode funcionar como uma genealogia do poder, chamando atenção para essas pequenas luzes que, mesmo em tempos de fascismos mais profundos, de redução da diferença, poderiam iluminar a noite com alguns lampejos de pensamento.

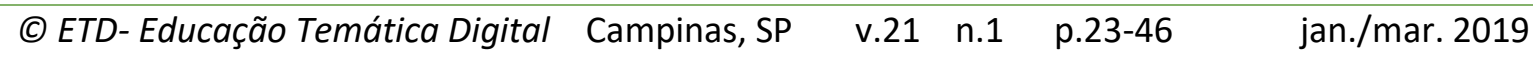


Podemos aqui tomar outra pista para montagem do pensamento e da escrita em educação, a montagem das diferenças. Na palavra e no campo da educação, existem muitas singularidades presentes e também um jogo de forças de seu aniquilamento, cabendo aqui uma questão: como pensamos os processos de montagem das diferenças na escrita em educação? Como pensar a diferença nas escritas em educação que vêm funcionando majoritariamente na perspectiva da identidade e da representação? Quais são os dispositivos que atravessam nossas relações com a linguagem, com a leitura e com a escrita?

O processo de montagem da escrita e do pensamento, entendemos nós, também é feito do colecionar, do catar trapos, restos, uma vez que "significa reivindicar-se colecionador de todas as coisas e, mais precisamente colecionador de trapos do mundo" (DIDI-HUBERMAN, 2015b, p. 119). Assim, a montagem do pensamento e da escrita em educação poderia ser pensada com os pequenos fragmentos catados de autores, colegas, professores, seminários, grupos de pesquisa, grupos de orientação, conversas que nos proporcionam as condições de possibilidade para desenvolver uma ideia, um conceito. Parece dizer o óbvio, mas somos catadores de palavras para a montagem da escrita e do pensamento. Todavia, isso desaparece em grande parte das escritas em prol de um texto limpo, higienizado, estruturado, que se mostra como pensamento conclusivo.

Como iniciamos dizendo, com Deleuze, a montagem está no intervalo. Lembrando, novamente, a imagem da máquina de Elida Tessler, podemos dizer que "todo o interesse está no intervalo da coisa desmontada e o tempo do conhecimento pela montagem" (DIDIHUBERMAN, 2015b, p. 140). Poderíamos ficar atentos e atentas à montagem da escrita em educação acontecendo no intervalo, no catar e colar, de uma palavra a outra. Porque é aí que coisas interessantes podem acontecer no pensamento.

A partir disso, esse conceito, que é também operado como procedimento filosófico, político e criativo, tem nos ajudado a pensar pequenos deslocamentos em educação. Isso porque buscaria entender quais são as ferramentas usadas nessa escrita, quais autores, quais modos de olhar são produzidos, tomando a escrita como montagem textual que produz imagens de pensamento, podendo ser imagens mais dogmáticas ou mais diferenciais (DELEUZE, 2009). Trata-se de interrogar o objeto e o próprio modo de olhar como, o que e por que escrevemos em educação e o que estamos nos tornando no presente.

Tal modo de lidar com o pensamento em educação funcionaria com o saber como corte descontínuo, buscando produzir outras ficções educacionais. Como seria possível pensar em uma montagem em educação que frature as coisas já feitas para gerar certo movimento? Isso não significa negar a tradição acumulada até aqui, mas produzir uma relação mais fabulativa e menos sagrada com ela. Como argumenta Skliar (2014), a escrita passa pelos processos de pertencimento cultural, de decifração de códigos, por moralização,
(C) ETD- Educação Temática Digital
Campinas, SP
v.21 n.1
p.23-46
jan./mar. 2019 
por tipos de utilitarismos e pela identidade. Mas passa também pela dificuldade em suportar o mundo e a si mesmo, pela experiência do limite, pela necessidade de ficcionar outras realidades para se continuar vivendo. Entretanto, trata-se de um uso da ficção não como o outro da verdade (uma vez que a própria verdade é uma ficção que esqueceu sua condição), mas como invenção e, portanto, afirmação (MOSÉ, 2016).

A montagem pode ser, assim, tomada como um ato de compreensão pedagógica, como montagem dos sintomas do presente, um choque entre as imagens fazendo com que se produza outra (DIDI-HUBERMAN, 2015b). A montagem como procedimento ocupa-se dos trapos, dos pormenores que dão legibilidade a um conjunto de pensamento que desloca e inquieta. As escritas acadêmicas produzidas em educação dão-se em específicos campos discursivos, em relações de forças que disputam sentidos e produzem modos de pensar e existir.

Por isso, quando Deleuze (2006) problematiza a imagem dogmática do pensamento, é justamente para deslocar o pensar como solucionador de problemas, como explicação ou reflexão, para o ato de colocar problemas. O pensar estaria vinculado à experiência, uma vez que esta seria "[...] fruto de um encontro com um signo alheio que desde sua exterioridade nos modifica, nos apaixona, nos faz padecer. Só pensamos quando somos provocados desde fora do nosso poder, de nosso saber, de nossa identidade pessoal" (LÓPEZ, 2008, p. 55).

Assim que escrever sobre educação implicaria pensar o que estamos vivendo nesse campo e como somos afectados, pois maneiras de pensar e viver estão implicadas nos modos de ler e escrever. Daí a necessidade de se escapar, em frestas, do senso comum, do bom senso, da recognição, colocando em dúvida o próprio pensamento, fazendo criar aquilo que ainda não existe (CORAZZA, 2006).

Uma escrita operada por montagem, que buscaria funcionar como procedimento filosófico, criação artística e gesto político, problematiza os efeitos de verdade e nossos modos de existência para criar outras possibilidades. Desse modo, a escrita funcionaria como um gesto, um ato "[...] para ver se existe uma intensidade que produza alguns efeitos" (CORAZZA, 2006, p. 26).

Escrever sobre as imagens é inicialmente escrever. [...] É procurar todas suas energias na própria escritura, é abrir as possibilidades poéticas e filosóficas de conseguir algo - uma palavra, um texto, um estilo particular que daria conta dessa imagem particular - a partir de uma mudez primeira. É preciso, por isso, uma espécie de coragem: coragem de olhar, olhar ainda, coragem de escrever, escrever apesar de tudo. (DIDI-HUBERMAN, 2006, p. 3).

A escrita e o pensamento em educação, atravessados pelo conceito de montagem, poderiam, pois, produzir possibilidades de tomarmos a escrita como uma prática de si

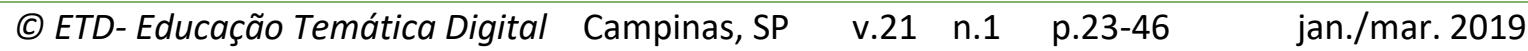


(FOUCAULT, 2004, 2011), como um modo mais intensivo de nos conduzirmos, como diria Aquino (2011). Um tipo de experiência que corte o saber, que faça com que nos estranhemos com a vida, que transforme o que pensamos e o modo como vivemos, em brechas. Como não renunciar ao exercício de pensamento quando escrevemos em educação?

A partir disso, podemos pensar, junto com Larrosa (2016), que talvez operar com a escrita como montagem do pensamento em educação nos faça pensar que a leitura e a escrita não são somente uma tarefa do pesquisador, o seu meio de trabalho, mas também o seu problema. Seriam uma operação que, além de problematizar teorias e métodos, problematiza a própria escrita, quando ela é tomada não como mera expressão do pensamento, mas como possibilidade de pensar de outros modos. Dessa forma, para DidiHuberman (2010; 2011; 2013d; 2015b), o conhecimento não está separado de seu estilo.

Questionamos tanto a necessidade da liberdade da pesquisa em educação, do espaço público e coletivo de se dizerem várias coisas e de vários lugares, mas esquecemos que o que é dito e escrito está disciplinado para dizer como tem que ser dito, de um modo (LARROSA, 2016). E isso é muito diferente da defesa de um vale-tudo na escrita acadêmica em educação ou da defesa do isto ou aquilo. Não se advoga por uma escrita que abandone sua função expressiva e comunicativa. É claro que não. Não se trata da escolha pelo pensar ou pelo saber acumulado, pelo sentido ou pela significação, porque necessitamos do acúmulo de toda a tradição, das questões técnicas e tudo mais. O que estamos querendo dizer é apenas que a repetição do mesmo desse acúmulo e produzida da mesma forma corre o risco de operar uma escrita afastada das forças e dos problemas que lhe dão sentido (LÓPEZ, 2008).

Um texto acadêmico precisa ser compreensível e generoso, mas isso não garante que dará o que pensar. Por isso a necessidade de um texto que traga problemas, que dialogue com a tradição para pensar com os outros, que esteja envolvido com o mundo e não se apresente apenas como um sistema fechado de ideias, como ilustração de um pensamento pronto e como patrulha das fronteiras disciplinares. Isso porque "as palavras podem ser uma adaga, um escudo, um presente, um alimento, uma escuridão, uma luz, uma corda, uma chave de fenda, independente de seu significado convencional" (Ibidem., p. 96).

Trata-se de uma postura política de assumir-se nesse jogo, entendendo suas regras, mas não abrindo mão do exercício do pensamento (que se dá sempre em uma língua, e não em um vazio abstrato), e de afetar e ser afetado pelo exercício de vida, leitura e escrita em educação. Se escrevemos em uma área que tem como forte temática a formação humana, como abrimos mão de nos formarmos, de nos transformarmos por meio de nossas práticas
(c) ETD-Educação Temática Digital
Campinas, SP
v.21 n.1 p.23-46
jan./mar. 2019 
de escrita? Como nos colocarmos e colocarmos nossas escritas junto a outras escritas? Como montamos nossa escrita?

\section{REFERÊNCIAS}

ALMEIDA, Gabriela M. R. de. Ensaio, montagem e arqueologia crítica das imagens: um olhar à serie Historia(s) do Cinema, de Jean-Luc Godard. 2015. Tese (Doutorado em Comunicação, Programa de Pós-Graduação em Comunicação e Informação) - Universidade Federal do Rio Grande do Sul, Porto Alegre, 2015.

ALMEIDA, Gabriela M. R. de. Por uma arqueologia crítica das imagens em Aby Waburg, Andre Malraux e Jean-Luc Godard. Significação: Revista de Cultura Audiovisual, São Paulo, v. 43, n. 46, p. 29-46, dez., 2016.

AQUINO, Julio G. A escrita como modo de vida: conexões e desdobramentos educacionais. Educação e Pesquisa, São Paulo, v. 37, n. 3, p. 641-656, set./dez., 2011.

AQUINO, Julio G. Diálogos em delay: especulações em torno de uma temporalidade outra do encontro pedagógico. Educação e Pesquisa, São Paulo, v. 43, p. 311-326, 2017.

BENJAMIN, Walter. Passagens. Belo Horizonte/São Paulo: UFMG/Editora Imprensa Oficial do Estado de São Paulo, 2009.

CAMPOS, Daniela Queiroz. Um saber montado: Georges Didi-Huberman a montar imagem e tempo. Aniki: Revista Portuguesa da Imagem em Movimento, América do Norte, p. 269288, maio 2017. Disponível em: http://aim.org.pt/ojs/index.php/revista/article/view/299 . Acesso em: 01 ago. 2017.

CORAZZA, Sandra M. Artistagens. Filosofia da diferença e educação. Belo Horizonte: Autêntica, 2006.

DELEUZE, Gilles. Cinema 1 - A imagem-movimento. São Paulo: Brasiliense, 1985.

DELEUZE, Gilles. A ilha deserta: e outros textos. São Paulo: Iluminuras, 2006.

DELEUZE, Gilles. Diferença e repetição. 2. ed. Tradução de Luiz Orlandi e Roberto Machado. Rio de Janeiro: Graal, 2006.

DELEUZE, Gilles. Cinema 2 - A imagem-Tempo. São Paulo: Brasiliense, 2007.

DELEUZE, Gilles. Cine I - Bergson y las Imágenes. Buenos Aires: Cactus, 2009.

DIDI-HUBERMAM, G. S'inquiéter devant chaque image. [11 de outubro de 2006]. Paris: Vacarme. N. 37, 2006. Entrevista com Georges Didi-Huberman realizada por Mathieu Potte-Bonneville e Pierre Zaoui. Disponível em: http://www.vacarme.org/article1210.html . Acesso em 15 de março de 2016. Traduzida para o português por Vinicíus Nicastro Honesko

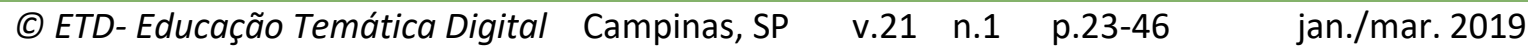


Disponível em: hhttp://flanagens.blogspot.com.br/2011/05/inquietar-se-diante-de-cadaimagem.html . Acesso em 15 de março de 2016.

DIDI-HUBERMAM, G. Un conocimiento por el montaje. Entrevista a Pedro G. Romero. Revista Minerva, Madrid, n. 05. 2007. Disponível em: http://www.circulobellasartes.com/revistaminerva/articulo.php?id=141. Acesso em 08 de março de 2015.

DIDI-HUBERMAM, G. Quand les images prennent position. L'oeil de L'Histoire, 1. Paris: Minuit, 2009.

DIDI-HUBERMAM, G. O que vemos, o que nos olha. São Paulo: Ed. 34, 2010.

DIDI-HUBERMAM, G. Atlas: como levar o mundo nas costas?. Trad. de Alexandre Nodari. Sopro, Panfleto Político Cultural, n. 41, dezembro de 2010a. Disponível em http://www.culturaebarbarie.org/sopro/n41.html . Acesso em: 19 de outubro de 2016.

DIDI-HUBERMAM, G. A sobrevivência dos vaga-lumes. Belo Horizonte: Ed.UFMG, 2011.

DIDI-HUBERMAM, G. Imagens apesar de tudo. Lisboa: KKYM, 2012a.

DIDI-HUBERMAM, G. Os brancos tormentos do testemunho. In: Palestra Culturgest, Lisboa, 2012b. Disponível em: https://vimeo.com/43378599. Acesso em: 16 de março de 2016.

DIDI-HUBERMAM, G. Quando as imagens tocam o real. PÓS: Revista do Programa do PósGraduação em Artes da escola de Belas Artes da UFMG, vol. 2, n. 4, nov. 2012c, p. 204-219. Disponivel em: http://www.eba.ufmg.br/revistapos/index.php/pos/article/view/60 . Acesso em: 22 de junho de 2015.

DIDI-HUBERMAM, G. A imagem sobrevivente: história da arte e tempo dos fantasmas segundo Aby Warburg. Rio de Janeiro: Contraponto, 2013a.

DIDI-HUBERMAM, G. Atlas ou a Gaia ciência inquieta. Lisboa: KKYM, 2013b.

DIDI-HUBERMAM, G. Cascas. São Paulo: Revista Serrote, 2013c.

DIDI-HUBERMAM, G. Cuando las imágenes tomam posición: el ojo de la história, 1. Espanha: A. Machado Libros, 2013d.

DIDI-HUBERMAM, G. Atlas do impossível - Waburg, Borges, Deleuze, Foucault. In: ARTIÈRES, P.; BERT, Jean-F.; GROS, F.; REVEL, J. (Org.). Michel Foucault. Tradução de Abner Chiquieri. Rio de Janeiro: Forense Universitária, 2014.

DIDI-HUBERMAM, G. A semelhança informe: ou o gaio saber visual segundo Georges Bataille. Rio de Janeiro: Contraponto, 2015a.

DIDI-HUBERMAM, G. Diante do tempo: história da arte e anacronismo das imagens. Trad. Vera Casa Nova, Márcia Arbex. Belo Horizonte: Ed. UFMG, 2015b.

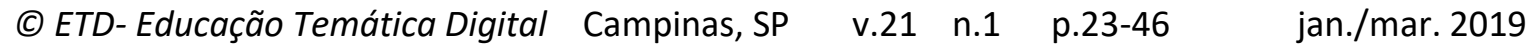


DIDI-HUBERMAM, G. Remontar, Remontagem (do Tempo). Cadernos de Leituras, n. 47. Belo Horizonte: Chão da Feira, 2016. Disponível em:

http://chaodafeira.com/cadernos/remontar-remontagem-do-tempo/. Acesso em: 17 de fevereiro de 2017.

DIDI-HUBERMAM, G. Quando as imagens tomam posição, os olhos da história, I. Belo Horizonte: EDitora UFMG, 2017.

FOUCAULT, Michel. As palavras e as coisas: uma arqueologia das ciências humanas. Trad. de Salma T. Muchail. São Paulo: Martins Fontes, 2002.

FOUCAULT, Michel. A escrita de si. In: FOUCAULT, Michel. Ética, sexualidade e política. Organização de Manoel B. da Motta. Trad. de Elisa Monteiro e Inês D. Barbosa. Rio de Janeiro, Forense Universitária, 2004.

FOUCAULT, Michel. A hermenêutica do sujeito: curso dado no Collège de France (19811982). Trad. de Marcio Alves da Fonseca, Salma Tannus Muchail. 3.ed. São Paulo: Martins Fontes, 2011.

GALLO, Silvio Donizetti de Oliveira. La production des hétérotopies à l'école: souci de soi et subjetctivation. Le Télémaque, Dijon, v. 47, p. 87-95, 2015.

GALLO, Silvio Donizetti de Oliveira Algumas notas em torno da pergunta: o que pode a imagem?. Revista Digital do LAV, Santa Maria, v. 9, p. 16-25, 2016.

HONESKO, Vinicius. Mãos ao alto: olhos armados. Sopro: panfleto político-cultural, n. 56, p. 2-10, 2011.

JACQUES, Paola Barenstein. Montagem Urbana: Uma forma de conhecimento das cidades e do Urbanismo. In: JAQUES, Paola Berenstein; BRITTO, Fabiana Dultra (Org). Experiências metodológicas para compreensão da complexidade da cidade contemporânea. Salvador: EDUFBA, 2015. p. 47-94.

KAFKA, Franz. A toca. Tradução de Francisco Agarez. Lisboa: LXXL Edições, 2009.

KOHAN, Walter Omar. Um exercício que faz escola: notas para pensar a investigação educacional a partir de uma experiência de formação no Rio de Janeiro. Educação em Foco, Juiz de Fora, v. 20, p. 159-175, 2015.

KOHAN, Walter Omar. Inventamos ou erramos: um princípio para pensar a dimensão filosófica da educação?. Itinerários de Filosofia da Educação, Porto, v. 13, p. 326-338, 2016.

LARROSA, Jorge. O ensaio e a escrita acadêmica. In: CALLAI, Cristiana; RIBETTO, Anelice (Org.). Uma outra escrita acadêmica: ensaios, experiências e invenções. Rio de Janeiro: Lamparina, 2016.

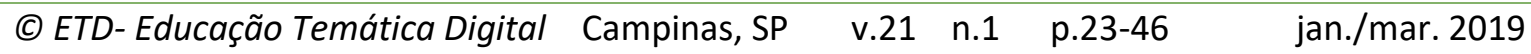


LÓPEZ, Maximiliano V. Acontecimento e experiência no trabalho filosófico com crianças. Belo Horizonte: Autêntica, 2008.

MOSÉ, Viviane. Nietzsche e a grande política da linguagem. 5.ed. Rio de Janeiro, Civilização Brasileira, 2016.

NIETZSCHE, Friedrich. Humano, demasiado humano. In: NIETZSCHE, Friedrich. Obras Incompletas. 3.ed. São Paulo: Abril Cultural, 1983.

NIETZSCHE, Friedrich. Genealogia da moral. Uma polêmica. Tradução de Paulo César de Souza. São Paulo: Companhia das Letras, 2006.

Ó, Jorge Ramos; AQUINO, Julio Groppa. Em direção a uma nova ética do existir: Foucault e a experiência da escrita. Educação e Filosofia, Uberlândia, v. 28, n. 55, 2014.

PUGLIESE, Vera. O conceito de montagem na obra de Georges Didi-Huberman. In: Coletivo do Mestrado em Artes do Instituto de Artes/UnB, 2005, Brasília-DF. Anais do II Coletivo do Mestrado em Artes do Instituto de Artes/UnB. Brasília - DF: PPG-Arte/VIS/IdA/UnB, 2005. p. 37-46.

SKLIAR, Carlos. Desobedecer a linguagem. Educar. Trad. de G. Lessa. Belo Horizonte: Autêntica, 2014.

VEIGA-NETO, Alfredo. Anotações sobre as relações entre teoria e prática. Educação em Foco, Juiz de Fora, v. 20, p. 113-140, 2015.

VEIGA-NETO, Alfredo; LOPES, Maura Corcini. Education and Pedagogy: a Foucauldian perspective. Educational Philosophy and Theory, v. 48, p. 1-8, 2016.

Revisão gramatical do texto sob a responsabilidade de: 